A. Taran, I. Garkusha, V. Taran, R. Muratov, V. Starikov, A. Baturin, T. Skoblo, S. Romaniuk and A.G. Mamalis

\title{
Structure and properties of nanostructured ZrN coatings obtained by vacuum-arc evaporation using RF discharge
}

ABSTRACT. Nanostructured films of zirconium nitride have been synthesized using an ion plasma vacuum-arc deposition technique in combination with a high-frequency (RF) discharge on AISI 430 stainless steel at $150{ }^{\circ} \mathrm{C}$. Structural examination using X-ray fluorescence (XRF), X-ray diffraction (XRD), scanning electron microscopy (SEM) with microanalysis (EDX), transmission electron microscopy (TEM), and nanoidentation was undertaken to reveal phase and chemical composition, surface morphology, microstructure and nanohardness of the coatings. The developed technology provided low-temperature film synthesis, minimized discharge breakdown decreasing formation of macroparticles (MPs) and allowed to deposit ZrN coatings with hardness variation 26.6-31.5 GPa and enhanced corrosion resistance characteristics. It was revealed that $\mathrm{ZrN}$ single-phase coatings of cubic modification with fine-crystalline grains of $20 \mathrm{~nm}$ in size were formed. The corrosion resistance of coatings has been tested in $0.9 \%$ quasiphysiological $\mathrm{NaCl}$ solution.

Keywords: coating, corrosion, RF-discharge, structure, vacuum-arc deposition, zirconium nitride

Nanotechnology Perceptions 14 (2018) 167-177

doi: 10.4024/N15TA18A.ntp.14.03 